\title{
Abstração e Empatia
}

\author{
Tammy Senra Fernandes Genú
}

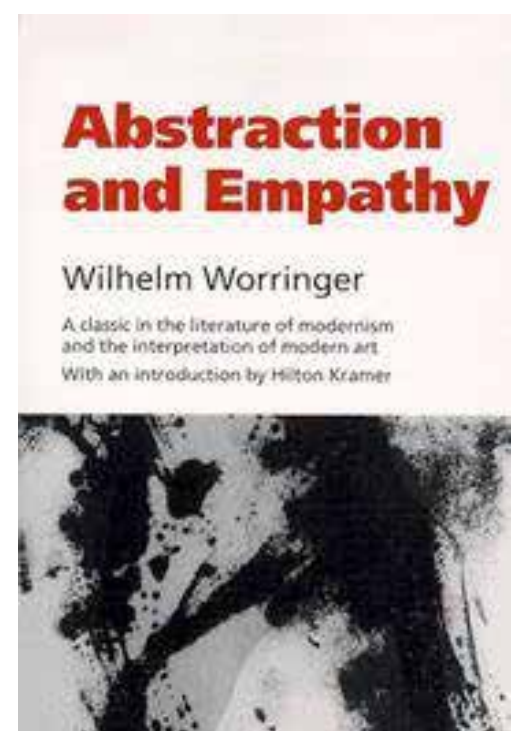

Resenha do livro

WORRINGER, Wilhelm. Abstraction and Empathy: a construction to the psychology of style. Chicago: Elephant Paperbacks, 1997.

\section{Credenciais do Autor}

Wilhelm Worringer foi um historiador da arte alemão muito conhecido por suas teorias sobre a abstração na arte. Influenciado pelos também historiadores Alois Riegl e Theodor Lipps, seu trabalho mais conhecido é justamente "Abstraction and Empathy", escrito em 1907 como tese de seu doutorado. Seu segundo livro "Form in Gothic", de 1911, de certa maneira 
expandiu as ideias das conclusões de seu primeiro livro. Ao longo de sua vida foi professor nas Universidades de Bern e de Bonn e escreveu vários outros livros, porém nenhum deles conseguiu atingir a importância de suas primeiras publicações, utilizadas como referência para inúmeras pesquisas até hoje.

\section{Resenha}

Ao fazer uma análise crítica do primeiro livro escrito por Wilhelm Worringer, é importante compreender os objetivos do autor com a obra. Frequentemente associado ao movimento expressionista alemão, é necessário entender que o autor não trata a respeito da abstração como conhecemos na arte moderna e nem teria como, já que este tipo de abstração surgiu a posteriori à publicação de sua tese. Worringer escreve a respeito de uma arte europeia do passado, para quem se provou moderna em suas premissas. ${ }^{2} \mathrm{O}$ autor busca demonstrar que, antes mesmo do naturalismo era a abstração que imperava na criação artística em grande parte das grandes nações. Para o autor, a estética moderna, baseada na teoria da empatia, é inaplicável aos setores mais amplos da história da arte (WORRINGER, 1994, p. 4). Dividido em duas partes, a primeira sendo "teórica", o autor trata a respeito dos princípios da Abstração e da Empatia e; na segunda parte, que ele considera "prática", ele dá exemplos da aplicação desta teoria nos ornamentos, na arquitetura, na escultura e na arte da pré-renascença. Por fim, o apêndice do livro é dedicado a análise da transcendência e da imanência na História da Arte pelo viés da abstração e empatia.

Para Worringer, é a condição da psique do artista que está na base de qualquer criação artística, a qual é resultado do relacionamento do artista com o mundo exterior, com a natureza a sua volta. Tendo isto em mente, Worringer nos apresenta a teoria de Lipps sobre empatia. De acordo com esse autor, ao contemplarmos um objeto, que pode ser de arte ou não, pode-se ocorrer dois fenômenos estéticos: a empatia positiva ou a empatia negativa. A primeira ocorre quando no momento de fruição o observador se 
vê no objeto e se envolve emocionalmente com ele, tendo como resultado desta experiência uma fruição prazerosa, um estado de repouso. Quando ocorre empatia positiva, podemos dizer que ocorre a sensação de prazer estético.

O artista somente consegue criar objetos que causem empatia positiva no espectador se estiver em simbiose com o mundo a sua volta, ou seja, somente se ocorrer uma relação harmoniosa do homem com o mundo exterior. Neste caso, o artista tem uma tendência ao antropomorfismo, procurando retratar os objetos sem distorção e de maneira orgânica.

No outro viés, temos também a empatia negativa, que ocorre quando esta fusão emocional do observador com a obra não acontece. 0 que surge é um conflito entre o espectador e aquilo que é visto, provocando uma sensação de desprazer na experiência estética. Neste caso, a criação artística ocorre por um fenômeno de outra natureza, diferente da via da empatia, por um impulso à abstração.

O autor vai além e cita Lipps mais uma vez ao dizer que é deste resultado que se tem as definições clássicas de beleza e feiura. Somente quando a empatia positiva ocorre é que as formas são consideradas belas:

Disto resulta as definições de beleza e feiura. Por exemplo "somente quando esta empatia existe as formas são consideradas belas. A beleza é esta liberdade ideal na qual consigo me ver e viver dentro dela. Por outro lado, uma forma é considerada feia quando sou incapaz de fazer isto. Quando não me sinto interiormente livre, quando me sinto inibido, sujeito a uma limitação da forma ou a uma limitação em sua contemplação". (LIPPS, 1906, p.247 apud WORRINGER, 1994$, p. 7$)^{3}$

Antes de nos adentrarmos no conceito de abstração feito pelo autor é interessante entender um outro conceito que ele nos trás, o conceito de volição artística. Como já citado, para o Worringer, todo trabalho de criação artística parte de uma demanda psicológica, da condição da psique do artista. Sendo assim, toda criação é resultado de uma volição artística, de uma vontade de criar. Ele define este conceito como sendo: 


\begin{abstract}
'Absoluta volição artística' pode ser entendida como aquela demanda latente que existe por si só, inteiramente independente do objeto e de seu modo de criação e que se comporta como vontade de criar. Este é fator primário em toda criação artística e, em sua essência mais íntima, todo trabalho de arte é simplesmente o resultado de uma objetificação desta já existente volição (WORRINGER, p. 9). ${ }^{4}$
\end{abstract}

Assim, para ele, até em última análise, a História da Arte era considerada como "História da Habilidade", porém, nesta nova abordagem, a evolução da História da Arte deve ser considerada como a "História da Volição", devemos compreender que a habilidade adquirida ou não por um artista é uma consequência de sua volição. Desta maneira, as diferenças de estilo na arte entre um período e outro não devem ser explicadas pelo ponto de vista da falta ou da presença de alguma habilidade de seus artistas, mas pelo fato de que estes artistas possuíam volições diferentes.

Na parte "prática" de seu texto o autor justifica o argumento da não evolução da arte egípcia pelo viés da volição. Neste momento, ele diferencia o ornamento grego, totalmente orgânico, do egípcio, com tendências abstratas, e diz ser incorreto afirmar, como Riegl fez, que a capacidade ornamental dos egípcios se exauriu. Se esta arte não se modificou ao longo dos anos, não foi por falta de habilidade, mas sim por que este resultado foi o desejado pelos artistas, a volição artística destes não se modificou. ${ }^{5}$ Ao contrário da volição artística dos gregos, que iniciou na abstração, com as linhas simples dos ornamentos das colunas gregas Dóricas e Jônicas e se modificou, até que o naturalismo, o orgânico, dominou, como pode ser visto nas colunas Coríntias.

Desta maneira, Worringer chega a um ponto muito importante. Todo estilo representa o máximo da felicidade para a humanidade que o criou. Este, para o autor deve ser considerado o dogma supremo de qualquer consideração a respeito de História da Arte. Aquilo que para o nosso ponto de vista parece uma deformação, pode ter sido de grande beleza para a humanidade que o criou. Assim, avaliações sobre arte utilizando somente a arte da antiguidade ou da renascença como pontos de referência podem 
ser considerados banais e cheia de absurdos. Uma das grandes importâncias então deste trabalho de Worringer foi justamente elencar a arte primitiva e a arte não europeia ao patamar que se dava à arte europeia até então.

Enfim, o que seria a abstração para o autor? Segundo ele, todo ponto tem seu contraponto, sendo assim o oposto do orgânico e do naturalismo é justamente a abstração, a capacidade de se extrair de um objeto suas formas mais básicas, fazendo com que adquiram uma configuração rígida e tendências geométricas. Sendo assim, para ele o contraponto da necessidade de empatia, a necessidade de se criar objetos que causem empatia positiva em seus observadores, é o impulso à abstração, à "necessidade" de se criar objetos com tendências geométricas, que, por vezes causarão empatia negativa em seus espectadores.

O impulso à abstração por parte do artista, assim como a necessidade de empatia, ocorre devido ao relacionamento deste com o mundo ao seu redor, porém este relacionamento é de uma natureza diferente. Neste caso, é resultante do temor e da angústia do homem perante o desconhecido da natureza. As formas abstratas, por possuírem uma regularidade, seriam uma das únicas maneiras nas quais o homem poderia repousar diante da confusão do mundo. Ao tratar sobre a abstração na arte primitiva, Worringer constata:

Não que o homem primitivo procurou mais urgentemente pela regularidade na natureza, ou viveu a regularidade maneira mais intensa; é justamente o contrário: é porque ele se encontra tão perdido e tão desamparado espiritualmente em meio as coisas do mundo exterior, é porque ele vive somente a escuridão e o capricho em meio a sua conexão com o mundo exterior que seu impulso a abstração é tão forte (WORRINGER, 1994, p. 18). ${ }^{6}$

Sendo assim, o impulso à abstração parte, como já tratamos acima, de uma volição: é o artista que, devido ao seu relacionamento com o ambiente em que vive, tem a "vontade" de criar objetos que tendem à abstração. A consequência crucial desta volição é justamente a representação do plano, de uma supressão da forma tridimensional, transformando o objeto em

\footnotetext{
"Not that primitive man sought more urgently for regularity in nature, or experienced regularitiy in it more intensely; just the reverse: it is because he stands so losta and spiritually helpless amidst the things of the external world, because he experiences only obscurity and caprice in the inter-connection and flux of the phenomena of the external world, that the urge is so strong in him to divest things of the external world of their caprice and obscurity in the world picture and to impart them a value of necessity and a value of regularity" (WORRINGER, Wilhelm. Abstraction and Empathy A contribution to the psychology of style. Chicago: Elephant Paperbacks, 1997. p. 18).
} 
uma única forma. Mais uma vez, é importante salientar que a utilização do plano por parte do artista não quer dizer que este não teria conhecimento a respeito da profundidade, ele simplesmente transforma essa profundidade em várias relações com os planos. Um exemplo, dentro da arte moderna desta volição, é arte cubista.

Worringer diz que a necessidade de empatia será sempre a busca do homem ao criar um objeto artístico, porém isso nem sempre é possível. Uma das grandes contribuições de seu trabalho foi, então, analisar o impulso à abstração e a importância que este impulso assumiu dentro da evolução da arte. Na análise de sua linha do tempo da História da Arte, que passa pela arte primitiva, egípcia, antiguidade clássica, renascimento e gótico, o autor ilustra que, a necessidade de empatia e o impulso a abstração foram se intercalando ao longo dos anos. Em alguns momentos, era a necessidade de empatia que predominava e, em outros, a necessidade de abstração.

Embora possamos relacionar o texto de Wilhelm Worringer aos desdobramentos da Arte Moderna, em nenhum momento isto é tratado em seu texto. O próprio autor, inclusive, não teria como prever o que ocorreu. Porém, é inegável a associação de seus escritos à arte de Paul Cézanne, ao Expressionismo Alemão e principalmente, ao Cubismo.

Recebido em: 20/10/2017

Aprovado em: 04/12/2017 